\title{
Sustaining Public Sector Lean Six Sigma: Perspectives from North America
}

\author{
John Maleyeff ${ }^{1, *}$ \\ ${ }^{1}$ School of Management, Rensselaer Polytechnic Institute, Hartford, CT, USA \\ *Correspondence: School of Management, Rensselaer Polytechnic Institute, 275 Windsor St, Hartford, CT, 06120, \\ USA. Tel: 1-860-478-5429. E-mail: maleyj@rpi.edu
}

Received: May 12, 2014

doi:10.5430/mos.v1n2p92
Accepted: June 7, $2014 \quad$ Online Published: June 30, 2014

URL: http://dx.doi.org/10.5430/mos.v1n2p92

\begin{abstract}
The aim of this research was to identify characteristics that sustained process improvement efforts in the public sector, with a focus on Lean Six Sigma as practiced in North America. The research methodology consisted of qualitative survey instruments, including open-ended questionnaires and in-depth interviews. The research found that public sector organizations encounter s number of implementation barriers not found in for-profit or not-for-profit non-public entities. A list of factors that drove both success and failure in short and long term process improvement implementations was generated. Based on this list, a set of success factors was developed and synthesized. The result was a common set of fundamental practices that were shared by public sector organizations that sustained their process improvement programs. Those factors were: (a) they deployed a sound, consistent, and robust methodology; (b) they built trust by removing fear; (c) they initiated long-term cultural change; and (d) they communicated the vision to all stakeholders.
\end{abstract}

Keywords: lean six sigma; public sector; process improvement; government

\section{Introduction}

In their quest to grow and prosper, many businesses have initiated a process improvement program to improve quality and productivity, with the goal of increased profitability. In recent years, two of the more popular programs of this type are Lean and Six Sigma. Lean Six Sigma is the name typically given to process improvement programs that attempt to implement an approach that is more robust than either Lean or Six Sigma individually (Arnheiter \& Maleyeff, 2005).

Many authors have argued that Lean and Six Sigma are simply newer versions of previous approaches. Public sector examples would include, but not be limited to, business process reengineering (Bowman \& Hellein, 1998), Total Quality Management (Daly, 2002), the Malcolm Baldrige National Quality Award criteria (Harwick \& Russell, 1996), and the International Organization for Standardization 9000 standards (Lowery, 1998). It is undeniable that Lean and Six Sigma include some aspects of these and other quality improvement methodologies.

In this article, success factors that lead to a sustainable process improvement program in the public sector are explored. The focus will be on Lean Six Sigma with occasional reference to other programs that use a participative, project-based methodology. Understanding the factors that lead to sustainability will be beneficial to administrators responsible for a wide range of public sector organizations that range in size from federal to local, and in function from revenue management to homeland security.

The project forming the basis of this research was funded by a research stipend from the IBM Center for The Business of Government. The remainder of this article is organized as follows. For readers unfamiliar with Lean Six Sigma, background is provided concerning their philosophical underpinnings and their toolbox of improvement approaches. After describing the research methodology, barriers to implementation are reviewed, and success factors that have been observed in the public sector are listed and described. The success factors are then synthesized into a cohesive set of four action items. The focus throughout is on implementation in government and certain other public sector enterprises. Due to their special nature, three categories of organizations are purposefully excluded from this 
discussion - schools, the military, and healthcare delivery.

\section{Background}

For a process improvement program to be successful, top executives need to consistently reinforce the notion that administrators have two important jobs - managing and improving. With Lean Six Sigma, improvement projects follow a prescribed mandate and structure meant to guarantee that important problems are attacked using a sound and consistent methodology. It is designed to avoid pitfalls common to efforts that address symptoms, rather than causes, of problems and enforce the use of data in decision making.

The consistency of approach provided by Lean Six Sigma is thought to enhance the effectiveness of project teams and facilitate the sharing of project results across the organization. When disciplined follow-up is implemented, results of project team recommendations can be tracked and evaluated. But, although some organizations have been able to sustain Lean Six Sigma or a similar process improvement program over the long term, others have abandoned their efforts after a period of time.

The genesis of Lean and Six Sigma to their current form is worth describing. Both include a collection of techniques as well as a comprehensive management approach. Some practitioners consider Lean and Six Sigma to be mutually exclusive although others see more similarities than differences (Snee 2005; Andersson et al, 2006). The origins of each approach and their philosophical roots are summarized below.

\subsection{Lean}

During 1949 to 1975, the Toyota Production System (TPS) gradually evolved into what is generally considered the gold standard of manufacturing effectiveness. Consequently, it has been the focus of many academic studies, perhaps most notably a study undertaken by the Massachusetts Institute of Technology (Womack et al, 1999). Lean can be defined as a management approach that seeks to maximize value to customers, both internal and external, while simultaneously removing wasteful activities and practices. Although the term "waste" is often used to describe a government program that does not contribute to the overall well-being of society, here the term is used to denote the non-value-added use of a service provider's time, such as time spent correcting an earlier mistake.

Lean Thinking (Womack \& Jones, 2003) introduced many practitioners to Lean, including a five-step application guide: (1) specify value from the customer's perspective, (2) identify the stream of processes used to provide value, (3) remove non-value-added activities from the value stream, (4) create pull by having all work is initiated by customer demand, and (5) strive for perfection. These steps would typically be applied during a one-to-five-day effort called "kaizen," where a multi-stakeholder project team would work full time on the project, often led by a professional facilitator known as a "sensei."

Lean principles are increasingly being applied to services, in particular healthcare (Fairbanks, 2007), and in the management of internal business processes (Maleyeff, 2006). But, Lean was originally motivated by competitive pressures in manufacturing and, as such, much of its jargon and many of its techniques apply to manufacturing operations. Thus, confusion often accompanies the application of Lean to services. For example, the relevance of the five-step guide is not apparent when applied to a service or business process where inventory as such generally would not exist (Maleyeff, 2006). However, many of the descriptive and intuitive tools of Lean apply nicely to services and its overall goals do not conflict with those of a service manager.

Successfully applying Lean requires a long-term viewpoint that considers all stakeholders, both internal and external. That is, Lean will only succeed if the organization's infrastructure reflects a common focus (Monden, 1993, p. 241). An example that illustrates the integration of the marketing, accounting, design, and sales departments to support Lean is provided by Emiliani (2003).

\subsection{Six Sigma}

In many ways the study of Lean has its roots in academe and therefore possesses a relatively consistent definition. But Six Sigma, with its roots firmly in industry, includes a more diverse set of definitions and viewpoints. Six Sigma can be defined as a management approach that seeks to maximize profits by systematically applying scientific principles to reduce variation and thus eliminate defects in product and service offerings. In 1986, the foundations of Six Sigma were established by Bill Smith at Motorola Corporation in response to product quality challenges. The application of Six Sigma contributed to Motorola's winning the Malcolm Baldrige National Quality Award in 1988.

The statistical meaning of the term "six sigma" (a statistical measure of variation that is achieved when each potential defect would have a very small chance of occurrence, usually expressed as 3.4 defects per million 
opportunities) has become less important as Six Sigma has evolved into a comprehensive management system. Many practitioners, however, continue to view Six Sigma as a set of techniques that promote variance reduction (Snee, 2005). The popularity of Six Sigma was boosted dramatically when it was adopted by GE Corporation under the leadership of Jack Welch. Although Six Sigma is most easily understood in a manufacturing context, it can and has been applied to healthcare and other services (Daniels, 2007). But it is not clear that all of the Six Sigma tools, particularly the statistically-based methods, are necessary in services or that service employees would be able to apply them as well as their more technically sophisticated counterparts in manufacturing.

Six Sigma projects are formalized and highly structured, making use of scientific approaches in the selection and management of projects. Six Sigma projects use a Define-Measure-Analyze-Improve-Control (DMAIC) structure, which is a systematic approach to organizing a process improvement project. The origins of DMAIC would be found in early quality programs such as the Plan-Do-Study-Act structure developed by Walter Shewhart in the 1930s (Shewhart, 1939, p. 45). Many practitioners consider DMAIC to be a primary reason for Six Sigma's success (de Koning \& de Mast, 2006). It enforces a high degree of discipline and commonality in project organization, problem solving tools, software, and terminology.

Six Sigma implementation would begin with executive education followed by training throughout the organization. Typically, formalized levels of training would be established with project and mentoring roles often defined by a "belt" level (e.g., master black belt, black belt, green belt, etc.). The tools of Six Sigma include well known problem solving techniques and popular statistical approaches, and a common software platform would usually be integrated to achieve a consistent means of internal communication. Six Sigma Black Belt certification is becoming a standard by which many quality practitioners are judged.

\subsection{Lean Six Sigma}

Despite their disparate roots, it is clear that Six Sigma and Lean encompass many common features, such as an emphasis on customer satisfaction, a culture of continuous improvement, the search for root causes, and comprehensive employee involvement. In each case, a high degree of training and education takes place, from upper management to the shop floor. But it is equally clear that differences exist. Lean managers tend to be somewhat holistic, satisfied with removing wasteful activities that hinder their ability to serve customers. Six Sigma managers tend to be financially driven, focusing directly on cost savings or revenue increases as the criteria for success.

It is easy to envision several varieties of Lean Six Sigma. A version offered here would be characterized as follows. The Lean influence would cause the organization to: (1) maintain an understanding of both internal and external customers' needs and desires, (2) seek to maximize the value-added content of all processes, (3) constantly evaluate employee incentives to ensure their alignment with system-wide performance objectives, and (4) look beyond strictly financially quantifiable cost savings. The Six Sigma influence would cause the organization to: (1) stress data-driven decisions that are based on facts, rather than opinions; (2) devote resources to solving problems that present significant challenges to business success; and (3) implement a consistent, highly structured project-based improvement regimen.

\section{Research Methodology}

Due to the investigative nature of this research, the political sensitivities, and the relatively small number of public sector administrators who have actively pursued Lean Six Sigma or a comparable improvement methodology over an extended period of time, qualitative research methods were used in this study. Qualitative methods are especially useful when measurement, per se, is not paramount. Sample sizes, which are generally fewer than about 40, are smaller than those found in surveys and other quantitative research methods. But qualitative research methods allow for a flexible response to unanticipated facts and newly discovered insights (de Ruyter \& School, 1998). This feature was useful in this research where some individuals were questioned on multiple occasions.

The primary qualitative methods employed were open-ended detailed questionnaires and in-depth interviews. Focus groups were not used for practical reasons (the need to assemble individuals who would likely need to travel great distances), and due to some of the pitfalls of focus groups that would compromise the integrity of the information obtained. For example, in focus groups, individuals often feel inhibited (Greenbaum, 1998), may feel social pressures (Webb, 1995), and tend to strive for group consensus even if no such consensus exists (Griggs, 1987). In-depth interviews, on the other hand, are especially useful in unique situations (Robson \& Fisher, 1989), allow for greater control over respondent selection (Cassell \& Symon, 2004), and can provide great depth and comprehensiveness (Hedges, 1985). A recent paper by Stokes and Bergin (2006) provides a comprehensive 
comparison of focus groups and in-depth interviewing.

The research began with the development of an open-ended written questionnaire that was posted on the Internet. Electronic notices (via professional group e-mail lists and on-line forums) were sent with the cooperation of numerous individuals and societies, most notable the Government division of the American Society for Quality, a professional organization that includes about 1,000 members in the U.S. and Canada (http://www.asq.org/government/). Some public sector professional groups refused to take part, indicating that their membership would be annoyed by being asked to complete a relatively long and detailed questionnaire.

The questionnaire included questions related to where improvement efforts were focused, how projects were chosen, the project teams' average size, level of commitment, overall project durations, the project management structure, the main process improvement techniques used during typical projects, and the improvement projects that were the most successful and why. In additional, potential barriers were listed and participants were asked to indicate those that presented them with a challenge. Finally, each participant was asked to provide specific advice to a public administrator wishing to initiate a comprehensive process improvement effort.

The questionnaires were completed by 25 experienced public-sector administrators. Extensive follow-up interviews with 15 public-sector administrators currently or previously involved in process improvement efforts were conducted. These audio-taped interviews lasted anywhere from 30 minutes to two hours, and allowed participants to elaborate on their experiences, specific projects, and the advice they chose to offer. In follow-up interviews, participants were asked to respond to hypotheses offered by the author pertaining to the sustainability of process improvement programs.

\section{Implementation Barriers}

Although many practitioners and academics consider Lean and Six Sigma to be collections of techniques that are rooted in the disciplines of industrial engineering and statistics, the empirical evidence has shown that the key to their effectiveness concerns organizational structure (for example, Park \& Gil, 2006, Achanga et al, 2006). In this regard, the history of Total Quality Management (TQM) in the public sector is relevant. In discussing TQM, McNabb and Sepic (1995) list the three main factors as organizational culture, operating climate, and organizational policies. Kim, Pindur, and Reynolds (1995) recommend creating a consistency between the improvement methodology and the culture of the organization. Connor (1997) stresses the role of middle management in the success of TQM and argues that the human cost can outweigh benefits. Lin and Ogunyemi (1996) list characteristics of TQM that are commonly misunderstood, including that it is a collection of techniques rather than a way of thinking. Finally, McGowan (1995) stresses the necessity to change management practices in order to effectively implement TQM.

The results of an analysis by Radin and Coffee (1993) remain relevant today. They argue that historically, the implementation of private sector programs in government has failed to consider "interdependencies between various program and organizational elements," in particular the lack of multiple stakeholder acceptance, and the conflict between the program's goal of employee empowerment and management's desire to maintain control. In discussing TQM, they recommend that implementation be considered for those organizations that possess a specified set of characteristics. Others have explored the factors that work to complicate the implementation of certain methodologies in the public sector after they had shown success in the private sector (for example, Lin \& Ogunyemi, 1996).

Through observation, questionnaire analysis, and interviews, a comprehensive set of barriers that could work to sabotage the implementation of Lean Six Sigma have been assembled. Some of the potential barriers that could occur in the private sector are found with greater frequency in the public sector, including inconsistent leadership motivation, management experience with process improvement, a culture that considers time devoted to improvement to be unproductive, union rules and relations, employees that are unable to apply sophisticated quantitative methods, and many undocumented processes.

Several additional challenges are particularly unique to the public sector. They include a general skepticism of government, distinctive human resource practices, the election cycle and term limits, stability and job security concerns, legislative controls, and competing special interests. Additionally, revenue is typically not directly linked to value, because most of the funding of services derives from tax revenue paid by citizens who traditionally have low expectations, making them relatively apathetic and therefore not likely to routinely complain or offer suggestions for improvement. 


\section{Research Results}

Organizations that have maintained a long standing and comprehensive process improvement program such as Lean Six Sigma possess many common features. It is clear that these features enhance their ability to sustain the efforts over a period of time.

(1) They have been inspired by influences emanating outside of the public sector, usually a leader with business experience;

(2) They have experienced little leadership turnover;

(3) They paved the way for the program's implementation by removing organizational barriers and modifying its culture;

(4) They focus on certain underlying principles and maintain a consistent conceptual framework, based on Lean and/or Six Sigma, or alternatively Total Quality Management, the Malcolm Baldrige National Quality Award guidelines, or the International Organization for Standardization family of standards;

(5) They began by employing a full time administrator to oversee the program's implementation, but this position was often considered temporary until the program was up and running so as not to create an unnecessary bureaucracy;

(6) They offer a guarantee to employees that no layoffs will result from a process improvement project;

(7) They make conscious efforts to communicate program successes internally, such as posting project results electronically or placing story boards in prominent locations;

(8) They face similar challenges, revealed by responses to a question asking respondents to consider a list of 20 potential organizational barriers, where most respondents chose the majority of the list as at least somewhat troublesome; and

(9) They did not achieve success overnight, with most taking several years to create a culture that characterizes and sustains their program.

Similar features were also noted in successful individual projects, even in organizations that would not be characterized as progressive. These improvement projects concerned the improvement of a variety of service processes, including tax collection, security information review, pot hole repair, licensing services, and vehicle maintenance. These and other projects tended to employ a formalized project structure, similar to Define-Measure-Analyze-Improve-Control, at times with minor modifications. The tools used during the project were very basic techniques that are easy to apply by non-technical employees. These methods included many root cause analysis tools and some very basic statistical tools.

\section{Success Factors for Sustainability}

It is clear that management commitment to a Lean Six Sigma process improvement program must go beyond slogans, banners, or motivational speeches. The leadership team should exude a constancy of purpose, along with discipline and patience that allows the program to take root. The management team must be made responsible and accountable for both managing the organization and improving its effectiveness. The creation of an infrastructure that sustains requires attention be given to the following four actions, which were found in all successful programs:

(1) They deployed a sound, consistent, and robust methodology

The establishment of a consistent philosophical foundation, supported by an accompanying methodology, is critical. Leadership is best advised to focus on the methodology with which they are familiar, because the specific methodology is less important than a consistent and viable implementation strategy. The research uncovered successful implementation of Lean Six Sigma programs, along with other methodologies such as the Malcolm Baldrige National Quality Award criteria or Total Quality Management.

The foundation must be easy to understand but not be reduced to clichés. The research has found that successful programs share not a methodology, but a common set of principles. For example, they consider citizens to be customers rather than nuisances. And they also believe that individual employees can make a difference by generating ideas that can help management make positive change. Outside consultants can be helpful during early stages of program implementation. But they can also be a hindrance when their approach is inconsistent with the organization's culture or when they are seen as being held responsible for the program's success. 
Training needs to be consistent with the methodology and provided in a just-in-time manner, allowing employees to immediately apply the concepts and techniques covered. The creation of a common language, approach, and toolbox will enhance communication across the organization. The methodology, however, cannot be viewed as inflexible. It should be allowed to evolve as circumstances change, such as during times of leadership turnover.

\section{(2) They built trust by removing fear}

To obtain and maintain organizational-wide support, leaders should address the fear that will inevitably accompany Lean Six Sigma initiation. This fear is mainly due to job insecurities, including the possibility of layoffs or punishment for speaking honestly during project sessions. Leadership should be cognizant of the very real need for employee commitment. So, though it may appear that lowering costs through improvement will only occur with layoffs or other payroll cuts, successful programs focus on using normal attrition to reduce operating costs. Thus, a clear statement should be made by the leadership team guaranteeing that no layoffs will take place as a result of a process improvement activity. In some cases, for example, formal agreements between union and management were modified to contain the no layoff guarantee.

Over time, it should become apparent to union members and other employees that indeed they can benefit from Lean Six Sigma. In particular, their job satisfaction will increase as they are allowed to participate in determining how their job is done (Perry et al, 2006). Another benefit to both management and staff would be confidence that the efficiency and effectiveness of their operations compares favorably with those in the private sector, eliminating concerns of privatization.

Transparency is critical so that employees understand that Lean Six Sigma will provide a benefit rather than a threat. To this end, it is recommended that suggestions made during project meetings that affect quality of work life be taken seriously. One example was noted where employees asked for and received a new office refrigerator initiated by a suggestion made during a process improvement project, even though this action would not directly improve the service being analyzed.

\section{(3) They initiated long-term cultural change}

Gradual but steady implementation is generally preferred over a massive rollout that can give rise to a "this too shall pass" passive aggressive reaction. During this time, management at all levels must continuously reinforce a focus on "process" by avoiding the practice of assigning blame for start-up problems that occur. Supervisors must allow workers to devote attention to improving their work in addition to doing their work. And workers should see that tangible benefits can be derived from their participation in improvement efforts.

When management and staff on a project team are treated as equals, the line separating their responsibility blurs. Staff appreciate being able to control how their work is done. Managers appreciate having staff members who are motivated to provide excellent service to customers. Employees at all levels who are members of a process improvement team that makes improvement suggestions have a natural desire to see that their ideas produce favorable results.

Maintaining momentum is critical because the culture should be allowed to evolve naturally. Mistakes are likely, especially mis-communicating the program's intentions. In one case, when Lean was introduced into an organization, a rumor began that Lean meant "Less Employees Are Needed." In these cases leadership needs to take quick and decisive action. Often a focus on metrics can be counterproductive. For example, a seemingly reasonable tabulation number personal trained in Lean Six Sigma - often creates a focus on training for the sake of training rather than training for the sake of improvement. Arbitrary deadlines or timetables can also be counterproductive because circumstances change and the program should not be force-fit into the organization.

\section{(4) They communicated the vision to all stakeholders}

Because stakeholder involvement is critical, all affected constituencies should be kept abreast of the program's development early and often. This communication should also address the tangible benefits that should accrue each stakeholder, while avoiding promises that may not be realized. The phrase "under promise and over deliver" is appropriate.

Early communication with employees is a must. But management should be aware that not all employees have access to the same communications mechanisms as management. For example, certain employees may not be assigned an e-mail account or a mailbox. Once the communication is begun, feedback from employees should be encouraged because in many cases, an implementation detail can easily be changed to accommodate the needs of a constituency group. 
The leadership team should be involved in a clear, convincing, and vocal way. Making site visits, spending time in each training wave, and dropping in on project meetings are examples of leadership action that signals their commitment. Monitoring progress on a monthly basis through Lean Six Sigma status meetings may also be considered.

As projects commence, presenting the results internally using posters or other visible media, placed predominantly in a common work area, is worthwhile. Certain external customers, such as contractors, advocacy groups, and ordinary citizens can help spread the message if they can be convinced that the program is in their self-interest.

\section{Conclusion}

A disciplined process improvement methodology, such as Lean Six Sigma, can benefit any organization from large corporations to small municipalities. By focusing on intuitive techniques such as process maps, mistake proofing, and standardization, Lean Six Sigma is easily understood and highly transparent, enhancing communication and participation. If implemented wisely, Lean Six Sigma can be robust and adaptable.

But the program will not be effective without considerable employee involvement from top leadership to front-line employees. They must all believe that a personal benefit will result from their active involvement. If a process improvement program is to be sustained, cost reductions must be accomplished by improved service processes accompanied by a combination of attrition and workforce reallocation, rather than by cutting direct payroll costs through layoffs. If successful, capacity would be freed to provide additional services to the public. In this way, newly elected leaders may be motivated by a desire to enhance their status in the community in a very visible way.

For public-sector entities, the opportunities are great but only if the threats are well understood. Creating another bureaucracy or another mandate from headquarters must give way to an organizational-wide attitude that fosters a focus on citizens and their satisfaction. As we look into the future of process improvement in government, one thing is clear - we know what to do and we know how to do it. The methodology of Lean Six Sigma has borrowed freely from past quality initiatives while incorporating an improved implementation structure. It is hard to imagine a new and substantially improved methodology. The onus is squarely placed on leadership - there needs to be real understanding of the requirements for success and there needs to be real commitment to making the changes necessary to achieve a transformation.

\section{References}

Achanga, P., Shehab, E., Roy, R., \& Ne, G. (2006). Critical success factors for lean implementation within SMEs. Journal of Manufacturing Technology Management, $17(4), \quad 460-471$. http://dx.doi.org/10.1108/17410380610662889

Andersson, R., Eriksson, H., \& Torstensson, H. (2006). Similarities and differences between TQM, six sigma, and lean. The TQM Magazine, 18(3), 282-296. http://dx.doi.org/10.1108/09544780610660004

Arnheiter, E.D., \& Maleyeff, J. (2005). The integration of lean management and six sigma. The TQM Magazine, 17(1), 5-18. http://dx.doi.org/10.1108/09544780510573020

Bowman, J.S., \& Hellein R. (1998). Total quality management in Florida: Implementation in state agencies. Public Administration Quarterly, 22(1), 114-129.

Cassell, C., \& Symon, G. (2004). Essential Guide to Qualitative Methods in Organizational Research. London, UK: Sage Publishing. http://dx.doi.org/10.4135/9781446280119

Connor, P.E. (1997). Total quality management: A selective commentary on its human dimensions. Public Administration Review, 57(6), 501-509. http://dx.doi.org/10.2307/976961

Daly, J.L. (2002). Implications of organizational climate and ethical leadership on reengineering in municipal government. Public Administration Quarterly, 26(2), 198-217.

Daniels, S.E. (2007). Six Sigma at Cigna. Quality Progress, 40(5), 43-48.

de Koning, H., \& de Mast, J. (2006). A rational reconstruction of Six-Sigma's breakthrough cookbook. The International Journal of Quality and Reliability Management, 23(7), 766-787. http://dx.doi.org/10.1108/02656710610701044

de Ruyter, K., \& School, N. (1998). Positioning qualitative market research: Reflections from theory and practice. 
$\begin{array}{llllll}\text { Qualitative } & \text { Market Research: An International Journal, } & \text { 1(1), } & \text { 7-14. }\end{array}$ http://dx.doi.org/10.1108/13522759810197550

Emiliani, B.L. (2003). Better Thinking, Better Results. Kensington, CT: The Center for Lean Management.

Fairbanks, C.B. (2007). Using Six Sigma and Lean methodologies to improve OR throughput. Association of Operating Room Nurses Journal, 86(1), 73-82. http://dx.doi.org/10.1016/j.aorn.2007.06.011

Greenbaum, T.L. (1998). The Handbook for Focus Group Research. Thousand Oakes, CA: Sage Publishing.

Griggs, S. (1987). Analyzing qualitative data. Journal of the Market Research Society, 29(1), 15-34.

Harwick, B.T., \& Russell, M. (1996). A working model to help institutionalize quality improvements in local governments. The International Journal of Public Administration, 19(10), 1891-1913. http://dx.doi.org/10.1080/01900699608525169

Hedges, A. (1985). Group interviewing. In R.L. Walker (Ed.). Applied Qualitative Research. Aldershot, UK: Gower Publishing.

Kim, P.S, Pindur, W., \& Reynolds, K. (1995). Creating a new organizational culture: The key to total quality management in the public sector. International Journal of Public Administration, 18(4), 675-709. http://dx.doi.org/10.1080/01900699508525027

Lin, B., \& Ogunyemi, F. (1996). Implications of total quality management in federal services: the US experience. International Journal of Public Sector Management, 9(4), 4. http://dx.doi.org/10.1108/09513559610128654

Lowery, D. (1998). ISO 9000: A certification-based technology for reinventing the federal government. Public Productivity and Management Review, 22(2), 232-250. http://dx.doi.org/10.2307/3381035

Maleyeff, J. (2003). Benchmarking performance indices: pitfalls and solutions. Benchmarking: An International Journal, 10(1), 9-28. http://dx.doi.org/10.1108/14635770310457511

Maleyeff, J. (2006). Exploration of internal service systems using lean principles. Management Decision, 44(5), 674-689. http://dx.doi.org/10.1108/00251740610668914

McGowan, R.P. (1995). Total quality management: Lessons from business and government. Public Productivity and Management Review, 18(4), 321-331.

McNabb, D.E., \& Sepic, F.T. (1995). Culture, climate, and total quality management: Measuring readiness for change. Public Productivity and Management Review, 18(4), 369-385.

Monden, Y. (1993). The Toyota Production System (2nd Edition.). Norcross, VA: Industrial Engineering and Management Press. http://dx.doi.org/10.1007/978-1-4615-9714-8

Park, S., \& Gil, Y. (2006). How Samsung transformed its corporate R\&D center. Research Technology Management, 49(4), 24-29.

Perry, J.L., Mesch, D., \& Paarlberg, L. (2006). Motivating employees in a new governance era: The performance paradigm revisited. Public Administration Review, 66(4), 505-514. http://dx.doi.org/10.1111/j.1540-6210.2006.00611.x

Radin, B.A., \& Coffee, J.N. (1993). A critique of TQM: Problems with implementation in the public sector. Public Administration Quarterly, 17(1), 42-54.

Robson, S., \& Foster, A. (1989). Qualitative Research in Action. London, UK: Hodder \& Stoughton.

Shewhart, W.A. (1939). Statistical Methods from the Viewpoint of Quality Control (Graduate School, Department of Agriculture, Washington, DC, USA).

Snee, R.D. (2005). When worlds collide: Lean and Six Sigma. Quality Progress, 38(9), 63-65.

Stokes, D., \& Bergin, R. (2006). Methodology or 'methodolatry'? An evaluation of focus groups and depth interviews. Qualitative Market Research: An International Journal, 9(1), 26-37. http://dx.doi.org/10.1108/13522750610640530

Webb, J.R. (1995). Understanding and Designing Market Research. London, UK: The Dryden Press.

Womack, J.P., \& Jones, D.T. (2003). Lean Thinking (2nd Edition.). New York, NY: Free Press.

Womack, J.P., Jones, D.T., \& Roos, D. (1991). The Machine That Changed The World. New York, NY: HarperCollins Publishers. 